Sweet syndrome is still unknown; however, it is presumed to be a type of hypersensitivity reaction that leads to stimulation of a cascade of cytokines that precipitate neutrophil activation and infiltration. ${ }^{5}$ That is why corticosteroids and immunosuppressants have been successfully used as treatments. ${ }^{6}$ We chose a nonsteroidal antiinflammatory agent over a corticosteroid or immunosuppressant.

The most frequent conditions associated with Sweet syndrome are inflammatory bowel disease and hematopoietic neoplasm. ${ }^{5} \mathrm{~A}$ work-up revealed that the patient did not have these diseases. Cardiovascular involvement in Sweet syndrome is not so common. There are a few reports of cardiovascular involvement in patients with Sweet syndrome. ${ }^{7}$ Hayashi and associates ${ }^{8}$ reported a female patient with Sweet syndrome who underwent aortic and mitral valve replacement; this patient's native valves showed no neutrophil infiltration. Similarly, no inflammatory cells had infiltrated either the capsule or thrombus of our patient. We cannot find any definite relationship between LV thrombus and Sweet syndrome, and therefore we suggest that this is a case in which LV thrombus and Sweet syndrome simply coincided.

\section{References}

1. Wohlfarter T, Hopferwieser T, Schwaighofer H, Knapp E, Lechleitner M, Kunz F, et al. An idiopathic floating left-ventricular thrombus. Dtsch Med Wochenschr. 1991;116:808-11.

2. Sweet RD. An acute febrile neutrophilic dermatosis. Br J Dermatol. 1964;139:349-53.

3. Beppu S, Park Y-D, Sakakibara H, Nagata S, Nimura Y. Clinical features of intracardiac thrombosis based on echocardiographic observation. Jpn Circ J. 1984;48:75-82.

4. Paloheimo JA. Thread-like strand from right atrium into right ventricle as leader of freely moving ball thrombus. Br Heart J. 1973;35:223-5.

5. von den Driesch P. Sweet's syndrome. J Am Acad Dermatol. 1994; 31:535-56.

6. von den Driesch P, Steffan C, Zobe A, Hornstein OP. Sweet's syndrome: therapy with cyclosporine. Clin Exp Dermatol. 1994; 19:274-7.

7. Guia JM, Frias J, Castro FJ, Gracián M. Cardiovascular involvement in a boy with Sweet's syndrome. Pediatr Cardiol. 1999;20:295-7.

8. Hayashi I, Hosoda Y, Kawasaki S, Yamamoto T, Dohi S, Kawai S. Aortic and mitral valve replacement in a patient with acute febrile neutrophilic dermatosis (Sweet's syndrome): report a case. Surg Today. 2001;31:810-3.

\title{
Apolipoprotein E4 increases aortic atheroma burden in cardiac surgical patients
}

\author{
Lian K. Ti, MMed, G. Burkhard Mackensen, MD, Hilary P. Grocott, MD, FRCPC, Daniel T. Laskowitz, MD, \\ Barbara G. Phillips-Bute, PhD, Carmelo A. Milano, MD, Andrew K. Hilton, MB, BS, FANZCA, Mark F. Newman, MD, \\ Joseph P. Mathew, MD, and the Neurologic Outcome Research Group, Durham, NC
}

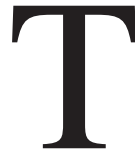
he increasing numbers of elderly patients undergoing cardiac surgery emphasizes the importance of identifying risk factors associated with adverse neurologic outcomes. Although the apolipoprotein $\epsilon 4$ allele $\left(A P O E^{*} E 4\right)$ has been identified as a risk factor, ${ }^{1}$ how its presence increases neurologic risk remains uncertain. Apolipoprotein $\mathrm{E}$ (ApoE) plays a key role in lipoprotein metabolism and has an important influence on the pathophysiology of atherosclerosis. ApoE's 3 major alleles $\left(A P O E^{*} E 2, A P O E^{*} E 3\right.$, and $\left.A P O E^{*} E 4\right)$

\footnotetext{
From the Divisions of Cardiothoracic Anesthesiology and Critical Care, Cardiovascular and Thoracic Surgery, and Neurology, Departments of Anesthesiology, Surgery, and Medicine, Duke University Medical Center, Durham, NC.

Supported in part by grants from National Institutes of Health (NIH) grant 1R01HL54316, Clinical Research Centers Program NIH MO1-RR-30, and American Heart Association Grant-In-Aid 95010970.

Received for publication Sept 3, 2001; accepted for publication May 22, 2002.

Address for reprints: Joseph P. Mathew, MD, Box 3094, Duke University Medical Center, Durham, NC 27710 (E-mail: mathe014@mc.duke.edu).

J Thorac Cardiovasc Surg 2003;125:211-3

Copyright $\odot 2003$ by The American Association for Thoracic Surgery

$0022-5223 / 2003 \$ 30.00+0$

doi: $10.1067 / \mathrm{mtc} .2003 .123$
}

result in differing susceptibility to dyslipidemia, atherosclerosis, and coronary heart disease. Therefore we sought to determine whether the $A P O E^{*} E 4$ allele influences aortic atheroma burden in patients undergoing cardiac surgery.

\section{Patients and Methods}

With institutional review board approval, a comprehensive transesophageal echocardiography examination was performed in 128 patients undergoing coronary artery bypass grafting surgery. For analysis, a videotaped frame displaying the most diseased area in each aortic segment was digitized. By tracing the outline of the atheroma, the area subtended by the atheroma was estimated (area of plaque). Similarly, the area of visualized aorta in the ascending aorta and aortic arch was measured by tracing the visualized segment of the aorta (Figure 1). The area of the visualized aorta in the descending aorta was measured by estimating the angle $(\alpha)$ subtended by the vessel wall and calculated as a portion of a circular or complete vessel $\left(\pi r^{2} \cdot \alpha / 360^{\circ}\right.$; Figure 1). Atheroma burden in each segment was then calculated as the percentage of area of the visualized aorta containing atheroma. Genomic DNA was used to determine $A P O E$ allele frequencies, as previously described. ${ }^{2}$ Differences between patients with and without the $A P O E^{*} E 4$ allele were compared by using the Wilcoxon rank sum test and the Fisher exact test. The association of atheroma burden and genotype was investigated with multivariable linear regression controlling for age, sex, and diabetes. 


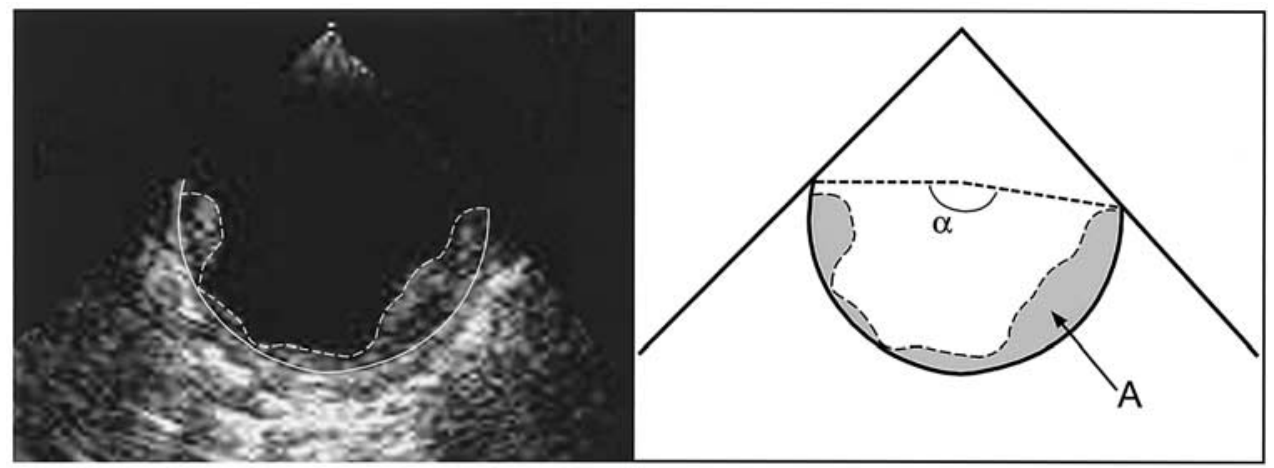

$$
\text { Atheroma Burden }=\frac{A}{\pi r^{2} \cdot \frac{\alpha}{360}}
$$

Figure 1. Atheroma burden in each aortic segment was determined as the ratio of the atheroma area $(A)$ to the total area of the aortic segment visualized. For the descending aorta, where the entire circumference could not always be visualized, the area of the visualized segment was adjusted according to the angle $(\alpha)$ subtended by that segment. $r$, Aortic radius.

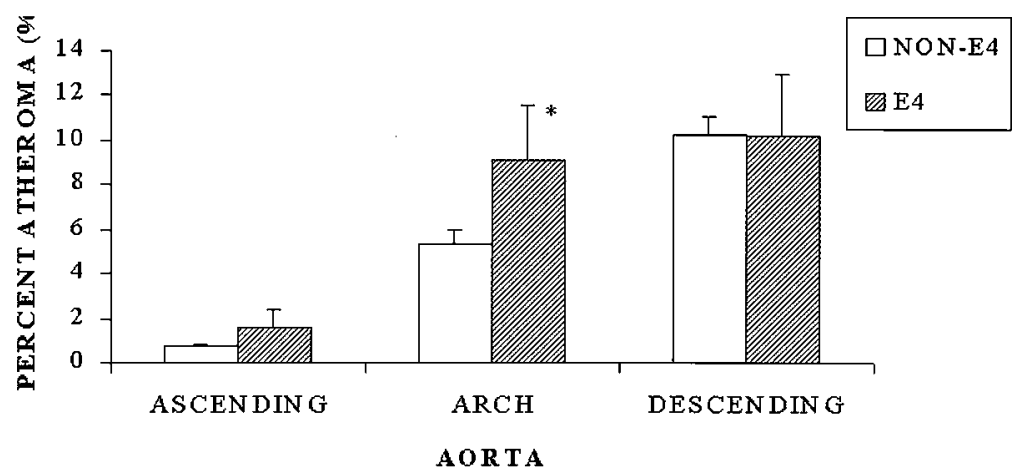

Figure 2. Bar graph with SE bars showing the influence of the $A P O E^{*} E 4$ allele on atherosclerosis in each segment of the thoracic aorta. The $A P O E^{*} E 4$ allele was associated with a significantly greater atheroma burden in the aortic arch. It was also associated with twice the atheroma burden in the ascending aorta, although this did not reach significance. ${ }^{*} P=.04$.

\section{Results}

The $A P O E^{*} E 4$ allele was present in $19 \%$ of the 128 patients enrolled. The mean percentage atheroma was greatest in the descending aorta $(10.2 \% \pm 8.9 \%)$ and least in the ascending aorta $(0.9 \% \pm 1.8 \%)$. In both the ascending aorta and the aortic arch, the atheroma burden was approximately 2 times greater in the $A P O E^{*} E 4$ group than in the non-APOE*E4 group $(P=.08$ and $P=.04$, respectively; Figure 2). Multivariable analysis revealed that the $A P O E^{*} E 4$ allele was significantly associated with atheroma burden in the aortic arch $(P=.046)$. The association between atheroma burden and $A P O E^{*} E 4$ trended toward significance in the ascending aorta $(P=.085)$ but not in the descending aorta $(P=$ .57). Age was also an important predictor of atherosclerosis both in the aortic arch and the descending aorta.

\section{Discussion}

The severity of aortic atherosclerosis has important ramifications on the neurologic outcome of patients undergoing cardiopulmonary bypass because atherosclerosis of the aorta has been correlated with an increased risk of stroke after cardiac surgery. ${ }^{3}$ Aortic atherosclerosis might result in cerebral embolization of atheroma debris during cannulation, crossclamping, or decannulation and possibly as a result of a sandblasting effect from the high-velocity jet exiting the aortic cannula. Our study shows that, independent of age, sex, and diabetes, the $A P O E^{*} E 4$ allele is associated with a greater degree of atherosclerosis in the aortic arch. The increased atheroma burden might be a mechanism by which $A P O E^{*} E 4$ contributes to postoperative adverse cerebral outcomes. 
Unlike the ascending aorta and aortic arch, there was no association between the descending aorta and $A P O E^{*} E 4$. Potential reasons for this include the fact that the progression of atherosclerosis in the aorta is influenced by the flow dynamics and wall shear stress within the segments of the aorta. ${ }^{4}$ For example, the higher ejection velocity in the ascending aorta might limit formation of plaques in this region. More importantly, the influence of age on atherosclerosis is very strong, with an incidence rising steadily with age. ${ }^{5}$ Because patients undergoing cardiac surgery are increasingly elderly, the effect of $A P O E^{*} E 4$ might be masked by the dominating influence of age on atherosclerosis, particularly in the descending aorta.

Limitations to our study include the fact that our technique uses a 2-dimensional, rather than 3-dimensional, image of a specific aortic segment. Nevertheless, the percentage of atheroma method that we used does at least account for total plaque area that can be visualized. Finally, epiaortic imaging is a more sensitive measure of assessing plaque in the ascending aorta, and it is possible that a greater degree of atherosclerosis might have been detected, with its use potentially improving the link between atheroma burden and the $A P O E^{*} E 4$ allele.

\section{References}

1. Tardiff BE, Newman MF, Saunders AM, et al. Preliminary report of a genetic basis for cognitive decline after cardiac operations. The Neurologic Outcome Research Group of the Duke Heart Center. Ann Thorac Surg. 1997;64:715-20.

2. Saunders AM, Strittmatter WJ, Schmechel D, et al. Association of apolipoprotein E allele epsilon 4 with late-onset familial and sporadic Alzheimer's disease. Neurology. 1993;43:1467-72.

3. Hogue CW Jr, Murphy SF, Schechtman KB, Davila-Roman VG. Risk factors for early or delayed stroke after cardiac surgery. Circulation. 1999; 100:642-7.

4. Stanton AV. Haemodynamics, wall mechanics and atheroma: a clinician's perspective. Proc Inst Mech Eng [H]. 1999;213:385-90.

5. Marschall K, Kanchuger M, Kessler K, et al. Superiority of transesophageal echocardiography in detecting aortic arch atheromatous disease: identification of patients at increased risk of stroke during cardiac surgery. J Cardiothorac Vasc Anesth. 1994;8:5-13.

\title{
Systemic allergic reaction to the percutaneous patent foramen ovale occluder
}

\author{
Kazuaki Fukahara, MD, ${ }^{a}$ Kazutomo Minami, MD, ${ }^{a}$ Nils Reiss, MD, ${ }^{a}$ Dieter Fassbender, MD, ${ }^{\mathrm{b}}$ and \\ Reiner Koerfer, MD, ${ }^{a}$ Bad Oeynhausen, Germany
}

$\mathrm{T}$ ranscatheter occlusion of an atrial septal defect or patent foramen ovale (PFO) has become an effective and less invasive alternative to cardiac surgery. ${ }^{1}$ A number of complications have been recognized. ${ }^{2}$ However, hypersensitivity or allergic reaction to the device itself has been not reported.

We treated a patient who had a systemic allergic reaction to the percutaneous PFO occluder. The case is described, and the therapeutic implication is discussed.

\section{Clinical Summary}

A 37-year-old woman with a PFO was admitted to our institution for transcatheter occlusion of her PFO. She had an episode of

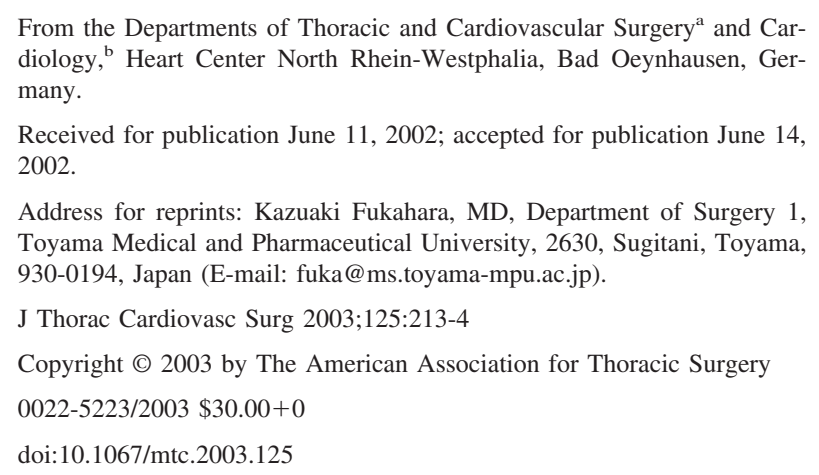

paradoxical cerebral embolism 1 year previously, and anticoagulation therapy with phenprocoumon had been initiated. Despite anticoagulation therapy, the patient had a transient ischemic attack 6 months before admission. She was offered the option of transcatheter occlusion of her PFO, and she agreed to the procedure. The patient had slight exertional dyspnea (New York Heart Association class I-II) but had no body weight change or fever at the time of admission.

Transvenous occlusion of the PFO was performed with a PFOStar device (Cardia Inc, Burnsville, Minn) by using a $30-\mathrm{mm}$ umbrella under transesophageal echocardiographic guidance. The postinterventional studies showed that the position of the device was satisfactory, and there was no residual shunt.

Two months after PFO occlusion, the patient began having dyspnea, a temperature of $38^{\circ} \mathrm{C}$, and dependent edema. Endocarditis or infection of the device was suspected, and she was referred back to our institution. Laboratory examination revealed a white blood cell count of $8800 \mathrm{mg} / \mathrm{dL}$ (granulocytes, 51.9\%; lymphocytes, $31.4 \%$; monocytes, $9.8 \%$; eosinophils, $5.7 \%$; and basophils, $1.2 \%$ ), a hemoglobin concentration of $14.5 \mathrm{~g} / \mathrm{dL}$, a hematocrit level of $43.2 \%$, a platelet count of $256,000 / \mathrm{dL}$, and a C-reactive protein concentration of $0.8 \mathrm{mg} / \mathrm{dL}$; other biochemical indices were within normal limits. Echocardiography with color Doppler scanning showed no residual shunt, no findings suggestive of intracardiac vegetation, and good cardiac function. Blood cultures were performed several times, but each showed no growth. Her history was significant for allergic reactions to some medications 